\title{
How does climate change affect mesoscale catchments in Switzerland? - a framework for a comprehensive assessment
}

\author{
N. Köplin ${ }^{1,2}$, D. Viviroli ${ }^{1,2}$, B. Schädler ${ }^{1,2}$, and R. Weingartner ${ }^{1,2}$ \\ ${ }^{1}$ Institute of Geography, University of Bern, Bern, Switzerland \\ ${ }^{2}$ Oeschger Centre for Climate Change Research, University of Bern, Bern, Switzerland
}

Received: 2 February 2010 - Revised: 2 June 2010 - Accepted: 9 June 2010 - Published: 28 September 2010

\begin{abstract}
Within the framework of this study we identify mesoscale catchments in Switzerland that exhibit sensitivity towards a change in climate with a focus on alterations of the water balance and peak flow conditions. For this study, the hydrological modelling system PREVAH is used, which is a semi-distributed and conceptual yet process-oriented model forced with hourly meteorological input on basis of a spatial resolution of $500 \times 500 \mathrm{~m}^{2}$. We calibrate the model where measured discharge records are available and transfer the calibrated model parameters to ungauged catchments through regionalisation, to arrive at a comprehensive set of model parameters for the entire area of Switzerland. To assess future changes, we apply an extensive set of 16 Regional Climate Models (RCMs) to the catchments. The RCM data are downscaled to a dense network of meteorological stations for the period from 2021 to 2050 using the Delta Change Approach. This downscaling method incorporates a bias correction of the RCM output and provides change rates and values for precipitation and temperature.

In the present paper we describe the application of a calibration and regionalisation procedure developed previously for Northern Alpine catchments to Southern catchments. The necessity to differentiate between a Northern and a Southern Alpine region, with their distinct climatologic and physiogeographic features, has proved true as the calibrated parameter sets show systematic differences between those regions, e.g. for the runoff forming parameters percolation rate (PERC) or storage time for quick runoff $(\mathrm{KOH})$. For the Southern Alpine area, we calibrated two thirds of the available catchments, i.e. 23 out of 36 , successfully for standard and flood conditions according to a combined model score of a linear and logarithmic Nash-Sutcliffe-Efficiency (NSE, $\left.\mathrm{NSE}_{\mathrm{ln}}\right)$ and a mean annual volumetric deviation $\left(\mathrm{VD}_{\mathrm{a}}\right)$. The
\end{abstract}

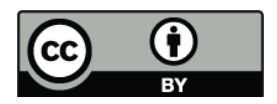

Correspondence to: N. Köplin (nina.koeplin@giub.unibe.ch) rate of successfully calibrated catchments is rather small in comparison with the results for the Northern Alpine catchments, where 140 out of 159 calibrations have been successful, and the distribution of the Southern catchments is more irregular. However, as the median NSE and NSE $\mathrm{ln}_{\mathrm{n}}$ as well as the range of $\mathrm{VD}_{\mathrm{a}}$ show an overall good model fit, a successful regionalisation may be expected. Next steps are the regionalisation of the Southern Alpine model parameters and the application of climate scenarios to the complete set of catchments, i.e. about 200 Swiss mesoscale catchments with an average area of $150 \mathrm{~km}^{2}$. Thus we can identify process-based relationships between climate sensitivity and catchment characteristics and provide quantitative information on future water balance and peak flow conditions of Swiss mesoscale catchments.

\section{Introduction}

The state of Baden-Württemberg has adapted its Act to Improve Preventive Flood Control to the latest findings from the KLIWA project (KLIWA, 2010) that suggests applying a flood adjustment strategy to stave off the consequences of an anticipated climate change. From now on, the determination of design floods has to account for a climate change by adding a climate factor to the $\mathrm{HQ}_{\mathrm{xx}}$ flood runoff (KLIWA, 2006).

In Switzerland, the Advisory Body on Climate Change (OcCC) formulates recommendations on questions regarding climate and global change. The OcCC assumes future climate conditions for Switzerland that are comparable to those expected for Southern Germany, i.e. an intensification of the climate system with an increasing frequency of extreme precipitation and flood events (OcCC, 2007). Therefore, the question arises whether the Swiss authorities have to adjust the procedure for determining design floods in Switzerland, too (KOHS, 2007; Schädler et al., 2007). Or is the increasing

Published by Copernicus Publications on behalf of the European Geosciences Union. 
frequency of flood events in the last decades just a small sample of a longer series, where periods with few and frequent floods alternate as an analysis by Schmocker-Fackel and Naef (2010) suggests? How will our hydrological systems change in general, if the climate system changes significantly?

The predominant majority of existing climate change impact studies is based on a rather coarse resolution of the employed scenarios both in space and time, in many cases adapted from monthly or seasonal mean values (e.g. Braun et al., 2000; Hagg et al., 2007; Kleinn et al., 2005). More detailed investigations, on the other hand, are restricted to mere case studies (e.g. Bultot et al., 1992, 1994; Gurtz et al., 2003; Jasper et al., 2004; Middelkoop et al., 2001; Verbunt et al., 2007).

Impact studies today lack in quantitative assessments of a range of different catchment types, and they also lack in high spatial and temporal resolution of the input data. The latter, particularly, is an essential prerequisite as soon as flood estimation is desired. In addition, so far no study accounts for a change in land cover that a change in climate typically involves, e.g. a decrease of glaciated areas or a shift of tree line.

Our study is unique in terms of examining a broad spectrum of hydrological systems distributed over the entire area of Switzerland from the lowlands to the high Alpine catchments with highly resolved input data and scenarios, and assessing not only the impact of a range of climate scenarios, but also a change in land cover, i.e. glaciated and forested area.

\section{Study setup and data}

The present study is part of the joint research project Climate Change in Switzerland - Hydrology (CCHydro; Volken, 2010), which has been initiated by the Federal Office for the Environment (FOEN) in 2008. Several national research institutions are involved, each of them accounting for a specific aspect of possible climate change impacts on hydrological systems in Switzerland. Within CCHydro, several questions will be investigated in subprojects, concerning the impacts of climate change e.g. on the water balance of Swiss mesoscale catchments and large basins, on the peak flow and low flow conditions, on glacier melt and runoff as well as water temperature. Highly resolved scenarios for the hydrologically relevant climate variables are provided, as well as scenarios for glacier retreat and changes in forest cover. These are essential input data for the impact studies executed in all subprojects, which constitutes an added value as the findings will be consistent with respect to the implemented scenarios.

In the subproject that is introduced here, we identify mesoscale catchments exhibiting sensitivity to a change in climate, and quantify the alterations of the water balance and its components, followed by a detailed analysis of the changes in peak flow conditions. We calibrate a hydrologi- cal model for catchments where measured discharge data is available. However, the number of catchments with uninfluenced records is limited, due to the high hydropower density in Switzerland (Margot et al., 1992), and their spatial distribution is unbalanced, especially in mountainous regions. Consequently, the model parameters obtained with calibration have to be transferred to ungauged catchments through regionalisation to arrive at a comprehensive set of model parameters for arbitrary mesoscale catchments in Switzerland. Subsequently, the hydrological model is forced with scenario data serving as climate input. This facilitates a quantitative assessment and the identification of catchments that are particularly sensitive to a change in climate. Additionally, land use change scenarios are applied to account for the sensitivity provoked by a change in glaciated area or forest cover.

\subsection{Study area}

Within the present study, we extend a calibration (Viviroli et al., 2009b) and regionalisation scheme (Viviroli et al., 2009c) which has been developed for and applied to Swiss Northern Alpine catchments in a preceding study to Southern Alpine regions as well (Fig. 1). Southern Alpine catchments are defined to be located to the south of the main ridge of the Alps, which incorporates the Inner Alpine valleys in cantons Valais and Grisons, too. To develop the regionalisation procedures, the Southern Alpine catchments were separated from the Northern ones because climatic and geomorphologic characteristics differ substantially between those regions, which might have hindered the process.

As soon as we have extended the regionalisation to the Southern Alpine area, a total of about 200 regionalised catchments (indicated as blue and red hatched areas in Fig. 1) are available for the application of climate scenarios. With an average area of $150 \mathrm{~km}^{2}$ and a range of 30 to $2000 \mathrm{~km}^{2}$ they fall into the category of mesoscale catchments. Those located downstream of larger lakes will not be considered, as their hydrographs are influenced too strongly by lake management. Hence, the slightly irregular distribution of regionalised catchments arises.

\subsection{Data base}

The required meteorological data are provided by $\mathrm{Me}$ teoSwiss (2008). The variables needed for model forcing are air temperature $\left({ }^{\circ} \mathrm{C}\right)$, precipitation $\left(\mathrm{mm} \mathrm{h}^{-1}\right)$, relative humidity $(\%)$, wind speed $\left(\mathrm{m} \mathrm{s}^{-1}\right)$, global radiation $\left(\mathrm{W} \mathrm{m}^{-2}\right)$ and relative sunshine duration (-). Depending on the type of meteorological station (Fig. 1), the resolution of the data is hourly to daily. For 77 stations of the automatic meteorological network (ANETZ) all variables are available in $1 \mathrm{~h}$ resolution, while 84 climate stations and 668 precipitation gauges provide data with a resolution of $6 \mathrm{~h}$ to daily, respectively. These data are interpolated to hourly data with help of the ANETZ data, while model forcing is mainly based on ANETZ data. 


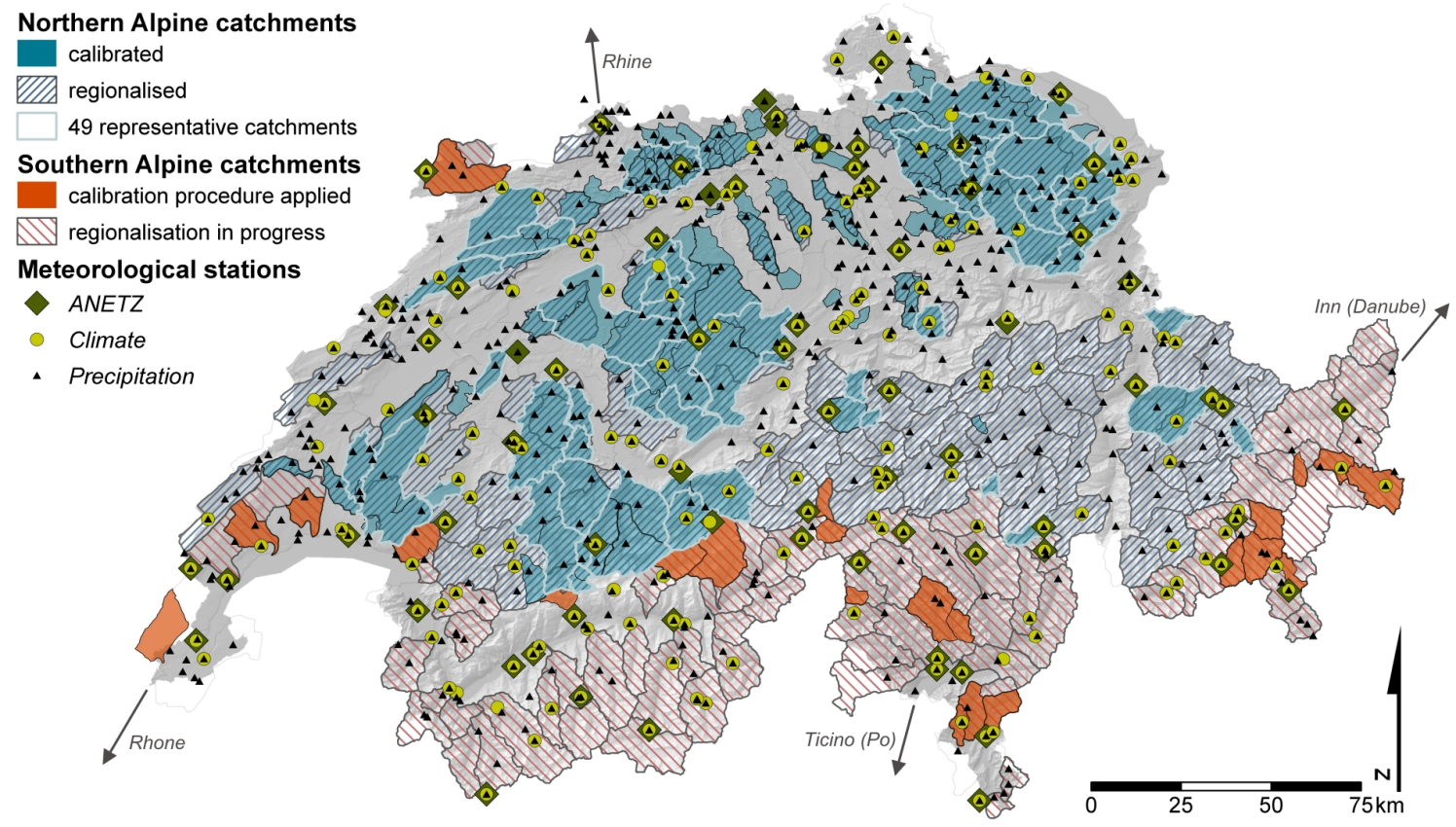

Fig. 1. Mesoscale catchments for calibration and regionalisation and meteorological network of Switzerland. Those catchments where model parameters were calibrated, validated and regionalised beforehand (Viviroli et al., 2009b,c) are indicated by blue colour, the Southern Alpine catchments presented in this study are shown in red. Note that a few catchments in northwest and west Switzerland belong to the Rhone basin draining southward.

As with the preceding study in the Northern Alpine region by Viviroli et al. (2009b), at least five years of discharge data in hourly resolution are available within the period from 1983 to 2005, which is the case for 36 catchments in the Southern Alpine region. One third of those show quality issues, though, which affects their applicability in the present study. The discharge records are provided mostly by the FOEN (2008) and partly by cantonal authorities.

Further input data for the modelling and regionalisation are a digital elevation model as well as maps of land use and soil properties, all of which are provided by the SFSO (2003).

\section{Methods}

The basics of the methods involved will be explained in this section. A complete documentation of the hydrological model used is available in Viviroli et al. (2009a), the calibration procedures applied are described by Viviroli et al. (2009b), and Viviroli et al. (2009c) describe the regionalisation scheme developed and tested for the Northern Alpine region.

\subsection{Hydrological modelling}

The hydrological modelling system PREVAH (PrecipitationRunoff-EVAporation-HRU related model; Viviroli et al., 2009a) is a semi-distributed and conceptual yet processoriented model that is run on the basis of hourly meteorological input, and at a spatial resolution of $500 \times 500 \mathrm{~m}^{2}$. We use this model in our study as it has been developed especially to suit conditions in mountainous environments. Furthermore, PREVAH has proved to be a reliable and flexible tool for various scopes of application and climate conditions ranging from drought analysis over water balance modelling to flood estimation and forecasting (Viviroli et al., 2009a).

The basic conceptualisation of PREVAH includes an HBV model component (Bergström, 1976; Lindström et al., 1997) that is implemented with the semi-distributed approach of hydrological response units (HRUs; Ross et al., 1979; Gurtz et al., 1999). Further modules supplement the model structure, each of which representing an individual process of the hydrological cycle, e.g. interception, soil water storage or snow accumulation and snowmelt as well as glacier melt.

The meteorological station data (Sect. 2.2) have to be interpolated, and the spatially distributed meteorological variables are averaged subsequently to $100 \mathrm{~m}$ altitude zones to force the model. In this case, interpolation is carried out on the basis of Detrended Inverse Distance Weighting (Viviroli et al., 2007), where detrending is based on elevation dependent regression of the climate variables.

\subsection{Calibration}

The calibration period, which proved suitability in the study by Viviroli et al. (2009b), covers five years from 1993 to 1997 in most cases, one year warm-up included. For catchments where these data are not available an alternative five 
Table 1. Grouping of parameters for successive pair-wise calibration of PREVAH (Viviroli et al., 2009b).

\begin{tabular}{llll}
\hline Pair & Parameter & Parameter description unit & Unit \\
\hline 1 & PKOR & Precipitation adjustment & $\%$ \\
& SNOKOR & Snow adjustment & $\%$ \\
2 & T0 & Threshold temperature snowmelt & ${ }^{\circ} \mathrm{C}$ \\
& TMFSNOW & Temperature melt factor for snow & $\mathrm{mm} \mathrm{d}^{-1} \mathrm{~K}^{-1}$ \\
3 & T0 & Threshold temperature snowmelt & ${ }^{\circ} \mathrm{C}^{-1} \mathrm{~mm} \mathrm{~h}^{-1} \mathrm{~W}^{-1} \mathrm{~m}^{2}$ \\
& RMFSNOW & Radiation melt factor for snow & $\mathrm{mm}$ \\
4 & SGR & Threshold storage for surface runoff & $\mathrm{h}$ \\
& K0H & Storage time for surface runoff & $\mathrm{h}$ \\
5 & K1H & Storage time for interflow & $\mathrm{mm} \mathrm{h}$ \\
& PERC & Percolation rate & $\mathrm{h}$ \\
6 & CG1H & Storage time for quick base flow & $\mathrm{mm}$ \\
& SLZ1MAX & Maximum content of the quick base flow storage & $\mathrm{h}$ \\
7 & K2H & Storage time for slow base flow & $\mathrm{mm} \mathrm{h}$ \\
& PERC & Percolation rate & $\mathrm{mm} \mathrm{d}^{-1} \mathrm{~K}^{-1}$ \\
$8^{\mathrm{a}}$ & ICETMF & Temperature melt factor for ice & $\mathrm{mm} \mathrm{h}^{-1} \mathrm{~K}^{-1} \mathrm{~W}^{-1} \mathrm{~m}^{2}$ \\
& ICERMF & Radiation melt factor for ice & \\
\hline
\end{tabular}

${ }^{\text {a }}$ For glaciated catchments only.

year period within the modelling period from 1983 to 2005 is chosen. Catchments are calibrated using an iterative search algorithm designed to maximize objectivity of the calibration procedure.

A total of 12 tuneable parameters (14 for glaciated catchments) are calibrated pairwise and sequentially. An overview of the calibrated parameter pairs is given in Table 1. Every model run is evaluated automatically using a combination of a Nash-Sutcliffe-Efficiency (NSE, Nash and Sutcliffe, 1970) with its logarithmic derivate ( $\mathrm{NSE}_{\mathrm{ln}}$ ) and a mean annual volumetric deviation $\left(\mathrm{VD}_{\mathrm{a}}\right)$ between observed and simulated runoff (Viviroli et al., 2009b). In each iteration step performed during a calibration, the best model run defines the limits of a reduced parameter space to be tested in the subsequent step. The tuneable parameters are calibrated for standard and flood conditions, the latter realised through an additional calibration run and evaluation of peak-flow-sensitive scores (Viviroli et al., 2009b). According to the objectives of our study, both parameter sets (standard and flood calibration) are used for further investigations.

\subsection{Regionalisation}

The parameter values obtained through calibration are transferred to ungauged catchments subsequently. The regionalisation scheme developed for the Northern Alpine region is a combination of three different approaches of parameter regionalisation (Viviroli et al., 2009c), namely Nearest Neighbours (parameter transfer from catchments similar in attribute space), Kriging (parameter interpolation in physical space) and Regression (parameter estimation from relations to catchment attributes).
A total of 82 attributes are collected for every catchment, e.g. geologic, physiographic or hydro-geologic attributes. They were chosen to describe the catchment characteristics best with a view to relevant hydrological, climatological and physiogeographic properties. Sets out of these 82 attributes are used in the individual regionalisation approaches. The resulting hydrographs of each method are combined to one hydrograph by computing their median for each time step. The results are evaluated by cross-validation with the jackknife-technique (Viviroli et al., 2009c).

\subsection{Climate scenarios}

Regional Climate Models (RCMs) with a minimum horizontal resolution of about $25 \times 25 \mathrm{~km}^{2}\left(625 \mathrm{~km}^{2}\right.$ cell area) provide the highest-resolution information available at the meso scale at the moment. This spatial resolution, however, is too coarse for the application in hydrological impact studies in mesoscale catchments. Still, RCM data are widely employed for this purpose. Another problematic issue related to RCMs are substantial biases of the model outputs. In this study, downscaling is executed using the Delta Change method (Prudhomme et al., 2002; Fowler et al., 2007). This procedure relies on the assumption that changes of the atmospheric mean state, as simulated by RCMs, are more trustworthy than the absolute value, which often shows large biases. By the Delta Change method, data for the much denser network of observation sites are provided, having an average density of one station per $60 \mathrm{~km}^{2}$ for precipitation, for example. Furthermore, the implementation of the Delta Change signal to generate the climate scenarios allows for a consistent modelling chain from interpolation of the meteorological 

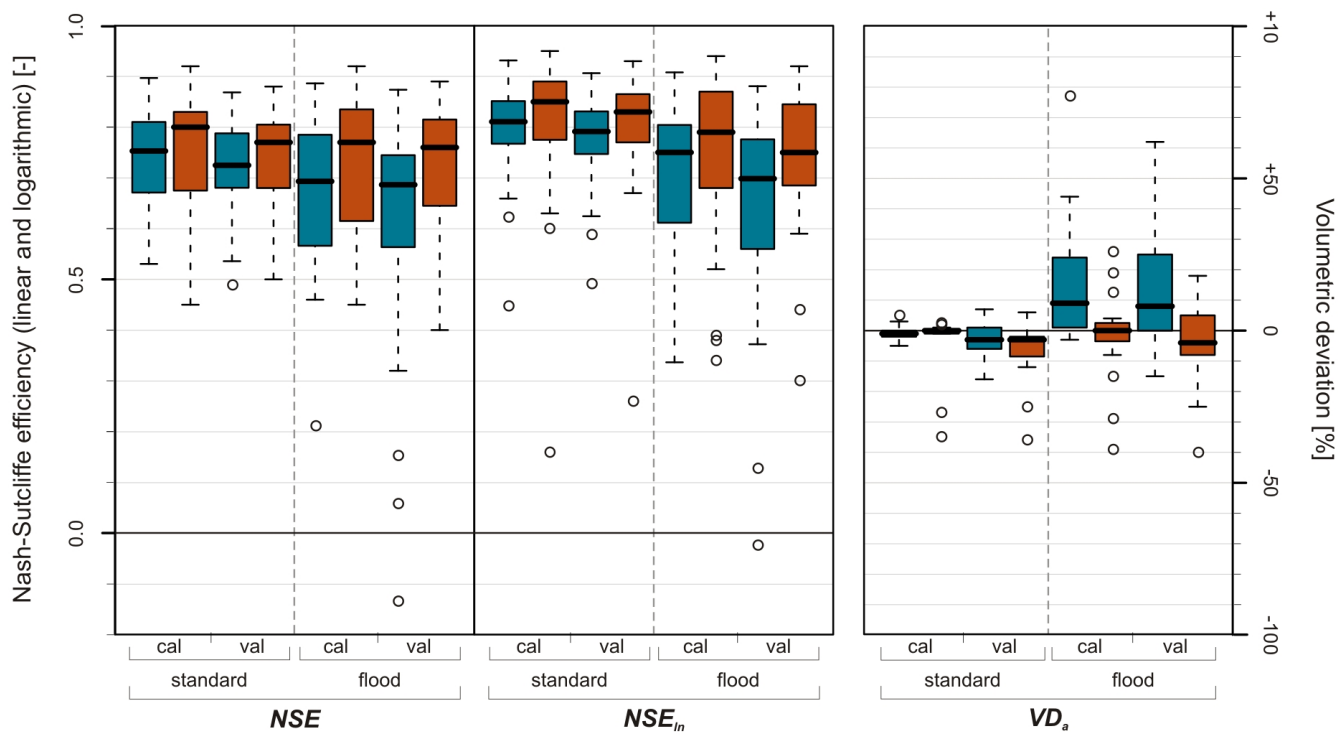

Fig. 2. Box plots for linear and logarithmic Nash-Sutcliffe-Efficiency (NSE, NSE 1 ) and mean annual volumetric deviation $\left(V_{D_{a}}\right)$ model scores from 49 representative Northern Alpine (blue boxes, Viviroli et al., 2009b) and 23 Southern Alpine catchments (red boxes) in calibration (cal) and validation (val) periods for standard and flood calibrated parameter sets. Circles denote outliers (distance from upper or lower quartile is greater than 1.5 times the quartile range; Tukey, 1977).

data (measurements and scenarios) for the individual catchment to forcing of the calibrated hydrological model. The Institute for Atmospheric and Climate Science (IAC) at ETH Zurich has compiled scenario data for temperature and precipitation as the hydrologically most important climate variables (Bosshard et al., 2009).

A total of $16 \mathrm{RCM}$ from the ENSEMBLES-project (Hewitt and Griggs, 2004) have been interpolated to meteorological station locations and the Delta Change signals have been identified. For each station the mean annual cycle of the Delta Change signal has been calculated for the period from 2021 to 2050 relative to the reference period from 1976 to 2005 with a moving averaging window of 31 days width. In comparison with a commonly used fixed averaging window, e.g. for every month, this allows for a better representation of the annual cycle of the Delta Change signal. Additionally, the annual cycle of the Delta Change has been smoothed with a harmonic model to filter out stochastic signals in the annual cycle. The daily Delta values thus calculated are added to (for temperature) or multiplied with (for precipitation) the observed time series to generate a set of climate scenarios with which the model is forced for the individual regionalised catchments.

\section{Results and discussion}

\subsection{Calibration}

Within the preceding study for the Northern Alpine region, a total of 140 catchments were calibrated successfully, of which 49 served as representative catchments for extensive evaluation due to their long gauge records covering the com- plete modelling period from 1983 to 2005 (Viviroli et al., 2009b; see Fig. 1). For the southern region, in contrast, 23 catchments constitute the total set of successfully calibrated catchments only. Out of the calibrated 36 catchments (Sect. 2.2), we had to dismiss 13, due to poor model efficiencies after calibration. In comparison with the northern catchments, where only 19 out of 159 calibrations failed, the proportion seems relatively high for the southern region. This can be attributed partly to the abovementioned quality issues with the discharge records, which contain several periods with missing data. Moreover, the interpolation of meteorological station data turned out to be a challenging task, owing to the marked topography in this part of Switzerland and the rather sparse distribution of ANETZ stations. Still, the calibration results of the 49 representative Northern Alpine and 23 successfully calibrated Southern Alpine catchments are compared, to assess them for systematic differences between the regions. This information might facilitate the subsequent regionalisation. Furthermore, we are able to verify the applicability of the calibration procedure to different climatic or physiogeographic regions.

Without exception, the medians of NSE and $\mathrm{NSE}_{\mathrm{ln}}$ are higher for the Southern Alpine catchments (Fig. 2, red boxes) compared to those of the Northern Alpine catchments (blue boxes). At the same time, the distributions of these efficiency scores are rather skewed. This suggests that the calibration results are more uniform for the Northern Alpine catchments. The comparatively small volumetric deviation of the Southern Alpine catchments might be ascribed to the effort we have made, identifying the best sample of meteorological stations for interpolation, which has been an essential step 

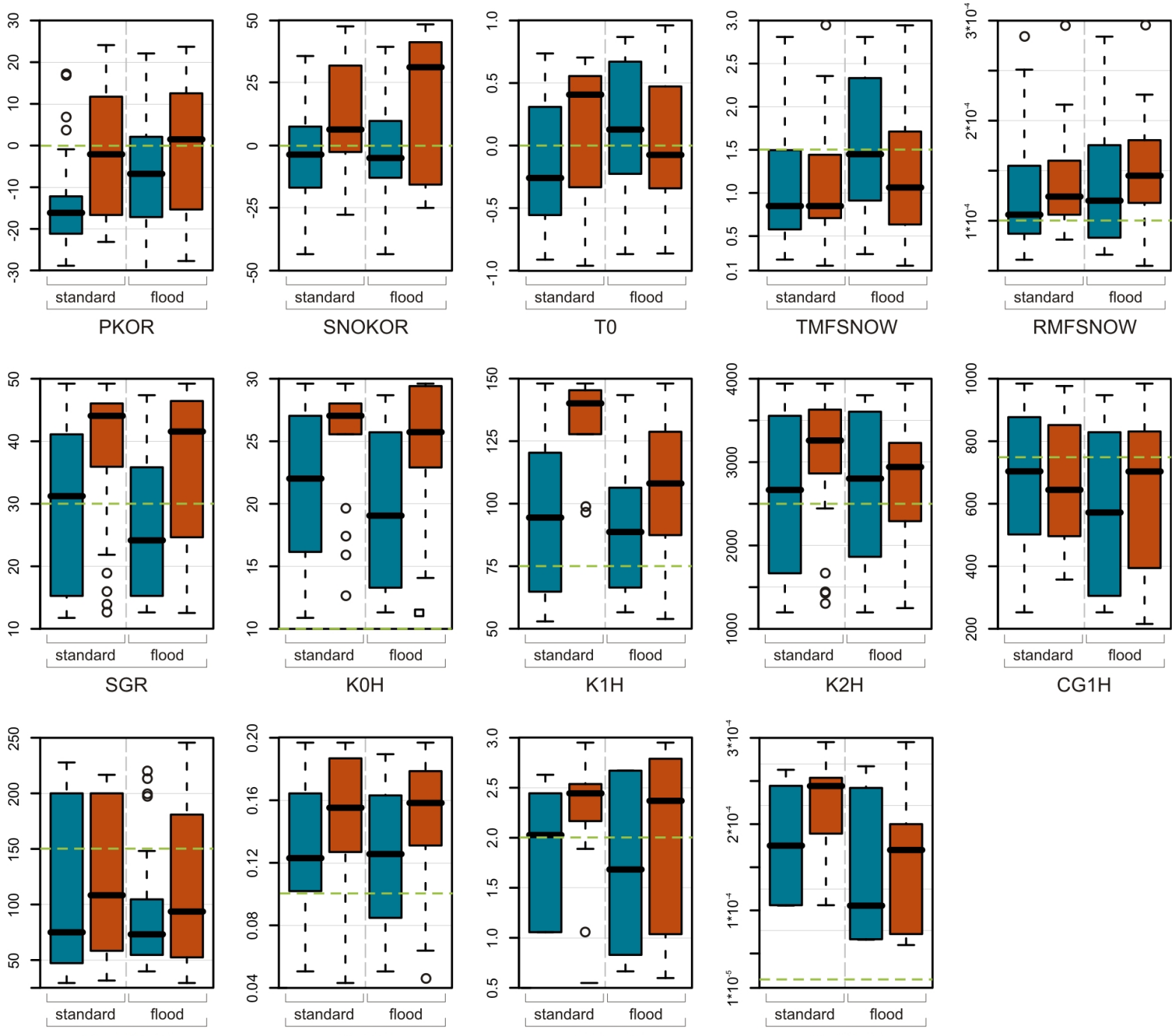

ICETMF

ICERMF

Fig. 3. Box plots for calibrated tuneable model parameters (for acronyms see Table 1) from 49 representative Northern Alpine (blue boxes, Viviroli et al., 2009b) and 23 Southern Alpine catchments (red boxes) for standard and flood calibration mode within the maximum calibration range. The initial value is indicated by a horizontal dashed green line. Circles denote outliers (distance from upper or lower quartile is greater than 1.5 times the quartile range; Tukey, 1977).

with respect to the small number of only 36 catchments for calibration here. This time-consuming procedure, however, was beyond the scope of the previous study by Viviroli et al. (2009b), where an extensive set of 159 catchments was assessed. The comparison of the overall model scores for the Northern and Southern Alpine catchments suggests that the iterative calibration procedure is capable to yield robust parameter estimation for the Southern Alpine region as well. The outliers (Fig. 2) of the Southern Alpine catchments can be attributed to short time series of measured discharge. For the Northern Alpine catchments the outliers are found mainly among small catchments with particularly quick reaction to intense precipitation.
Comparing the range of the calibrated parameter values (Fig. 3), systematic differences between the Northern and Southern Alpine catchments can be observed, which is evidence that the distinction between these two regions is reasonable. As with the model scores, the distributions of the calibrated parameters are rather skewed for the Southern Alpine catchments. The water balance adjustment parameters PKOR and SNOKOR, which are the most sensitive tuneable model parameters (Viviroli et al., 2009b), show noticeable higher values for these catchments, where high altitudes are poorly represented by meteorological stations. This might add to the significantly extended spread of PKOR and SNOKOR and to the clearly higher SNOKOR values, which is relevant because the catchments have relatively high mean altitudes. 
Payerne, $489 \mathrm{~m}$ asl, $46.81^{\circ} \mathrm{N}, 6.94^{\circ} \mathrm{E}$

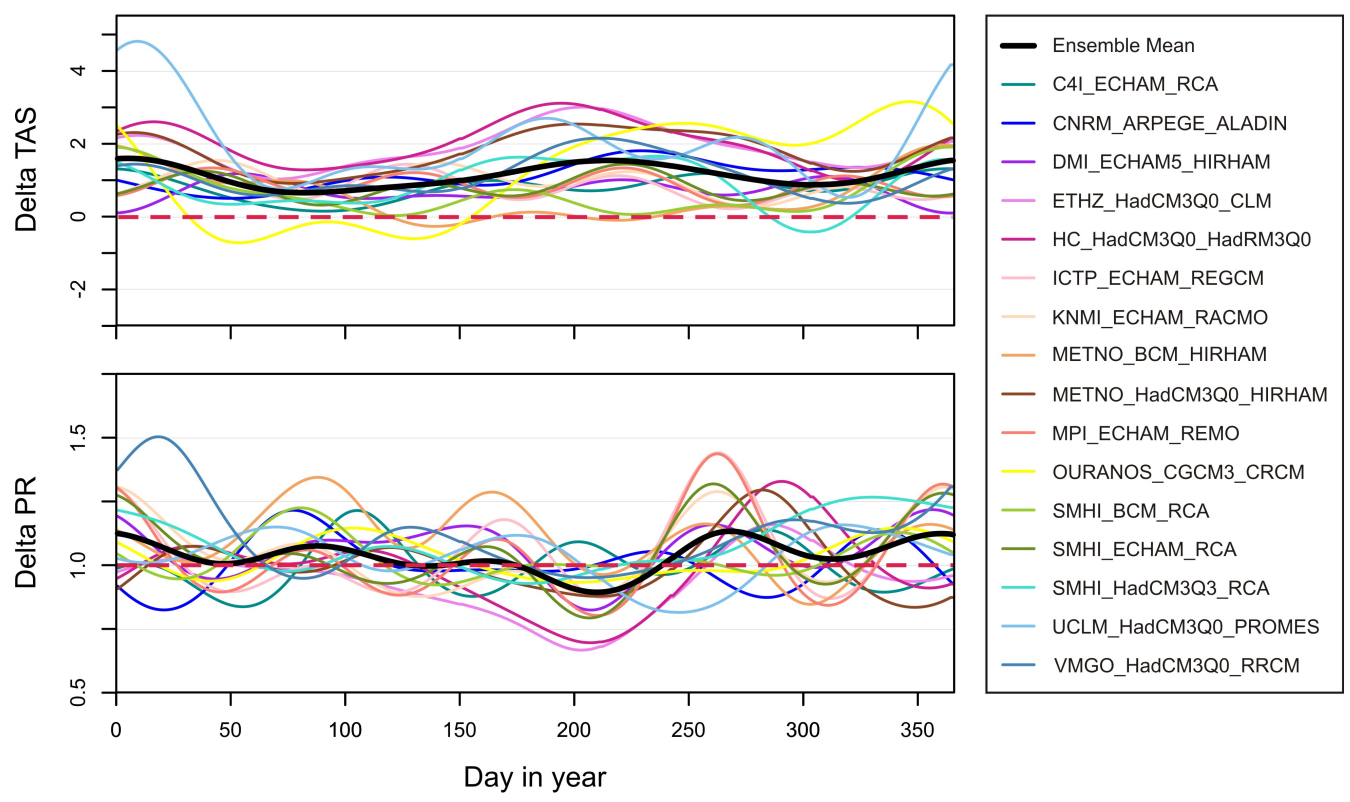

Fig. 4. Annual cycle of the Delta Change Signal for precipitation (PR) and temperature (TAS; Bosshard et al., 2009) using the example of Payerne. The abbreviations in the legend denote the model chain of each RCM as INSTITUTION_GCM_RCM. For all model chains the SRES emission scenario A1B (IPCC, 2000) was chosen, except for C4I_ECHAM_RCA where it was A2.

\subsection{Climate scenarios}

Delta changes are calculated for precipitation and temperature only, as it is the common practice in runoff impact studies (Fowler et al., 2007). Changes in the other hydrometeorological variables needed to force the hydrological model (Sect. 2.2) are not accounted for and will be kept constant when running the model with the climate scenarios, which is a very rough assumption, of course. However, as temperature and precipitation are the hydrologically most relevant climate variables, and the most sensitive tuneable model parameters rely on these variables, too, these simplifications are defensible.

The annual cycles of the Delta Change signal for temperature (TAS, Fig. 4) and precipitation (PR) exhibit obvious differences between the $16 \mathrm{RCMs}$, which is especially true for the change in precipitation. No clear pattern is observed, except for a statistically robust increase of autumn precipitation in the Northern Alpine region by about 15 to $25 \%$. Decreasing mean precipitation occurs in the summer months and has its largest amplitude of about -15 to $-25 \%$ in the Western and Southern part of Switzerland. For temperature the pattern is more homogeneous, the increase is strongest in the summer month and for the Alpine regions. The minimum increase can be observed in spring, and no decreasing temperatures are projected (Fig. 4).

\section{Conclusion and outlook}

In the present study, we introduce a framework in which we will assess the impact of climate change on hydrological systems in Switzerland through hydrological modelling with the semi-distributed and conceptual yet process-oriented PREVAH model (Viviroli et al., 2009a). Catchments that are sensitive towards a change in climate are determined and the alterations of their water balance and peak flow conditions will be quantified. Land use change scenarios are included in the framework to account for changes of the hydrological systems induced by changes in glaciated and forested area, additionally.

The investigations described in this paper involve the extension of a calibration and validation scheme, which has been developed for Swiss Northern Alpine catchments (Viviroli et al., 2009b,c), to Southern Alpine regions as well. Object of research are about 200 mesoscale catchments with a mean area of about $150 \mathrm{~km}^{2}$, ranging from 30 to $2000 \mathrm{~km}^{2}$. The hydrological model is run at hourly resolution and is forced with spatially and temporally highly resolved climate scenarios from 16 Regional Climate Models, downscaled to meteorological station data using the Delta Approach (Prudhomme et al., 2002).

We have calibrated two thirds of the investigated Southern Alpine catchments successfully for standard and flood conditions using the iterative search algorithm introduced by 
Viviroli et al. (2009b). The calibrated parameter sets differ systematically between the Northern and Southern Alpine region, which substantiates the distinction made before. Furthermore, this indicates that the calibration procedure is capable of accounting for catchment characteristics found in the Southern Alpine area, too, and yields robust parameter estimation. A regionalisation of the model parameters based on these calibrated catchments, however, we expect to be a challenging task due to the small overall number and their irregular distribution. This likely requires careful reconsideration and extension of the existing regionalisation scheme for the Northern Alpine catchments.

After regionalisation of the model parameters for the Swiss Southern Alpine areas, we will apply the climate scenarios for the entire area of Switzerland. To check the scenarios for hydrologic plausibility, we apply them to six test regions first, each of them representing a natural geographic region of the Northern Alps. The results of this plausibility tests will be evaluated, and the scenarios generating physically unreliable results will be excluded from further investigations.

On the basis of the previous results, we are confident to identify regions exhibiting climate sensitivity in the period from 2021 to 2050, and specify possible process-based relationships between sensitivity and specific catchment characteristics. Quantitative information on future water balance and peak flow conditions will be provided. The integration of land use change scenarios, i.e. an alteration of glaciated and forested area, will allow for an additional assessment of land use induced changes of hydrologic systems in Switzerland. As an extensive set of climate scenarios is in use, we will be able to specify the uncertainty range of our findings, too.

Acknowledgements. This study is funded by the Swiss Federal Office for the Environment (FOEN). The authors would like to thank the FOEN, the Swiss Federal Statistical Office (SFSO) and the Federal Office for Meteorology and Climatology (MeteoSwiss) for providing the necessary input data, as well as Thomas Bosshard (IAC ETHZ) for the calculation of the Delta Change signals.

Edited by: A. Wahren, F. Tavares Wahren, and K.-H. Feger Reviewed by: H. Bormann and another anonymous referee

\section{References}

Bergström, S.: Development and Application of a Conceptual Runoff Model for Scandinavian Catchments, University of Lund, SE, Bulletin Series A, No. 52, 134 pp., 1976.

Bosshard, T., Ewen, T., Kotlarski, S., and Schär, C.: The annual cycle of the climate change signal - An improved method for use in impact studies, Geophysical Research Abstracts (GRA), 11, EGU2009-7095, 2009.

Braun, L. N., Weber, M., and Schulz, M.: Consequences of climate change for runoff from Alpine regions, Ann. Glaciol., 31, 19-25, 2000 .
Bultot, F., Gellens, D., Spreafico, M., and Schädler, B.: Repercussions of a $\mathrm{CO}_{2}$ doubling on the water balance - A case study in Switzerland. J. Hydrol., 137, 199-208, 1992.

Bultot, F., Gellens, D., Schädler, B., and Spreafico, M.: Effects of Climate Change on Snow Accumulation and Melting in the Broye Catchment (Switzerland), Climatic Change, 28, 339-363, 1994.

FOEN (Federal Office for the Environment): Observed Discharge Time Series of Swiss Rivers, Bern, CH, 2008.

Fowler, H. J., Blenkinsop, S., and Tebaldi, C.: Linking climate change modelling to impacts studies: recent advances in downscaling techniques for hydrological modelling, Int. J. Climatol., 27, 1547-1578, 2007.

Gurtz, J., Baltensweiler, A., and Lang, H.: Spatially distributed hydrotope-based modelling of evapotranspiration and runoff in mountainous basins, Hydrol. Process., 13, 2751-2768, 1999.

Gurtz, J., Zappa, M., Jasper, K., Lang, H., Verbunt, M., Badoux, A., and Vitvar, T.: A comparative study in modelling runoff and its components in two mountainous catchments, Hydrol. Process., 17, 297-311, 2003.

Hagg, W., Braun, L. N., Kuhn, M., and Nesgaard, T. I.: Modelling of hydrological response to climate change in glacierized Central Asian catchments, J. Hydrol., 332, 40-53, 2007.

Hewitt, C. D. and Griggs, D. J.: Ensembles-Based Predictions of Climate Changes and Their Impacts, EOS T. Am. Geophys. Un., 85(52), 566, doi:10.1029/2004EO520005, 2004.

IPCC (Ed.): Special Report Emissions Scenarios, Summary for Policymakers, A Special Report of IPCC Working Group III, Geneva, 2000.

Jasper, K., Calanca, P., Gyalistras, D., and Fuhrer, F.: Differential impacts of climate change on the hydrology of two alpine river basins, Clim. Res., 26, 113-129, 2004.

Kleinn, J., Frei, C., Gurtz, J., Lüthi, D., Vidale, P. L., and Schär, C.: Hydrologic simulations in the Rhine basin driven by a regional climate model, J. Geophys. Res., 110, D04102, doi:10.1029/2004JD005143, 2005.

KLIWA: Our climate is changing, Consequences-ExtendStrategies, Impact on Water Resources Management in Southern Germany, LUBW "Landesanstalt für Umwelt, Messungen und Naturschutz" (State Environment, Measurement and Nature Conservation Agency) and "Bayerisches Landesamt für Umwelt” (Bavarian State Environment Agency, LfU), 2006.

KLIWA: http://www.kliwa.de/index.php?pos $=\backslash \&$ lang=en, last access: 31 January 2010.

KOHS: Auswirkungen der Klimaänderung auf den Hochwasserschutz in der Schweiz, Ein Standortpapier der Kommission Hochwasserschutz im Schweizerischen Wasserwirtschaftsverband (KOHS) (Impact of Climate Change on Flood Protection in Switzerland. A Position Paper of the Commission for Flood Protection of the Swiss Water Resources Society, KOHS), Wasser Energie Luft, 99, 55-57, 2007 (in German).

Lindström, G., Johansson, B., Persson, M., Gardelin, M., and Bergström, S.: Development and test of the distributed HBV-96 hydrological model, J. Hydrol., 201, 272-288, 1997.

Margot, A., Schädler, B., Sigg, R., and Weingartner, R.: Influence on Rivers by Water Power Stations $(>300 \mathrm{~kW})$ and the Lake Control, Hydrological Atlas of Switzerland, Plate 5.3, Federal Office for the Environment, Bern, CH, 1992. 
MeteoSwiss (Federal Office for Meteorology and Climatology): Time Series of Meteorological Variables, Zürich, CH, 2008.

Middelkoop, H., Daamen, K., Gellens, D., Grabs, W., Kwadijk, J. C. J., Lang, H., Parmet, B. W. A. H., Schädler, B., Schulla, J., and Wilke, K.: Impact of climate change on hydrological regimes and water resources management in the Rhine basin, Climatic Change, 49, 105-128, 2001.

Nash, J. E. and Sutcliffe, J. V.: River flow forecasting through conceptual models part I - A discussion of principles, J. Hydrol., 10, 282-290, 1970.

OcCC: Climate Change and Switzerland 2050, in: Impacts on Environment, Society and Economy, OcCC, Bern, CH, 2007.

Prudhomme, C., Reynard, N., and Crooks, S.: Downscaling of global climate models for flood frequency analysis: where are we now?, Hydrol. Process., 16, 1137-1150, 2002.

Ross, B. B., Contractor, D. N., and Shanholtz, V. O.: A finite element model of overland and channel flow for assessing the hydrologic impact of land-use change, J. Hydrol., 41, 1-30, 1979.

Schädler, B., Frei, C., Grebner, D., and Willi, H. P.: Grundlagen zum Klima (Climate Fundamentals), Wasser, Energie, Luft, 99, 58-60, 2007 (in German).

Schmocker-Fackel, P. and Naef, F.: More frequent flooding? Changes in flood frequency in Switzerland since 1850, J. Hydrol., 381, 1-8, 2010.

SFSO (Swiss Federal Statistical Office): GEOSTAT Database Products, Licence No. G158000315, @SFSO, Neuchâtel, CH, 2003.
Tukey, J. W.: Exploratory data analysis, Addison-Wesley, Reading, MA, 1977.

Verbunt, M., Walser, A., Gurtz, J., Montani, A., and Schär, C.: Probabilistic Flood Forecasting with a Limited-Area Ensemble Prediction System: Selected Case Studies, J. Hydrometeorol., 8, 897-909, 2007.

Viviroli, D., Gurtz, J., and Zappa, M.: The Hydrological Modelling System PREVAH, Geographica Bernensia P40, Institute of Geography, University of Bern, CH, 2007.

Viviroli, D., Zappa, M., Gurtz, J., and Weingartner, R.: An introduction to the hydrological modelling system PREVAH and its preand post-processing tools, Environ. Modell. Softw., 24, 12091222, 2009a.

Viviroli, D., Zappa, M., Schwanbeck, J., Gurtz, J., and Weingartner, R.: Continuous simulation for flood estimation in ungauged mesoscale catchments of Switzerland - Part I: Modelling framework and calibration results, J. Hydrol., 377, 191-207, 2009b.

Viviroli, D., Mittelbach, H., Gurtz, J., and Weingartner, R.: Continuous simulation for flood estimation in ungauged mesoscale catchments of Switzerland - Part II: Parameter regionalisation and flood estimation results, J. Hydrol., 377, 208-225, 2009c.

Volken, D.: CCHydro - Auswirkungen der Klimaänderung auf die Wasserressourcen und die Gewässer in der Schweiz, Hydrol. Wasserbewirts., 54, 143-146, 2010 (in German). 